\title{
GESTÃO E MARKETING EM UNIDADE DE INFORMAÇÃO: competências do profissional da informação
}

\author{
MANAGEMENT AND MARKETING IN INFORMATION UNIT: competences \\ of the information professional
}

Jade Gomes de Sousa Ferreira

UFC

Maria Aurea Montenegro Albuquerque Guerra

\section{RESUMO}

Apresenta o profissional bibliotecário e as possibilidades de se inserir no mercado de trabalho, mostrando como as transformações na sociedade repercutem na sua atuação em unidades de informação. O objetivo desse estudo é mostrar que o profissional da informação contemporâneo tem necessidade de diferentes perfis e competências de atuação, dentre esses a gestão voltada para a aplicação das ferramentas do marketing. Utilizou-se como metodologia a pesquisa bibliográfica, realizada em artigos e livros de autores que são expoentes na gestão e em marketing. Os resultados indicam que as ferramentas de marketing contribuem para um alcance maior da divulgação de produtos e serviços em unidades de informação. Seu alcance estende-se para uma proposta de gestão de toda unidade de informação. Conclui-se que atualização e conhecimento dos profissionais da informação, com novas estratégias de gestão, são condições emergentes.

Palavras-chave: Gestão e marketing em unidade de informação. Profissional da informação contemporâneo. Bibliotecário.

\section{ABSTRACT}

It presents the professional librarian and the possibilities of insertion in the work market, showing how the transformations in the society have repercussion in its action in information units. The objective of this study is to show that the contemporary information professional needs different profiles and performance skills, among which the management focused on the application of marketing tools. The methodology used was bibliographic research, carried out based on articles and books written by authors who are exponents in management and marketing. The results indicate that the marketing tools contribute to a greater reach of the dissemination of products and services in information units. Its scope extends to a management proposal for the entire information unit. We conclude that updating and knowledge of information professionals, with new management strategies, are emerging conditions.

Keywords: Management and marketing in information units. Professional of contemporary information. Librarian. 


\section{INTRODUÇÃO}

As mudanças são evidentes em todas as esferas da vida, seja ela social, econômica, política, científica, tecnológica e, não menos importante, profissional. $\mathrm{Na}$ composição desse pensamento, torna-se essencial discutir a influência do marketing na gestão em unidades de informação, tendo como ponto de partida o reconhecimento da profissão de bibliotecário como uma das mais antigas; portanto, mais passível de sofrer as alterações oriundas das transformações sociais é que esta pesquisa se impõe. Tal imposição refere-se ao modo de como o bibliotecário acompanha as transformações e se alia a elas no seu fazer cotidiano. Neste sentido, o marketing se apresenta como uma estratégia ou possibilidade de tornar a ação do bibliotecário mais competitiva, signo da sociedade contemporânea.

Essas alterações giram em torno da informação, de sua geração, armazenamento e disseminação. Segundo Castro (2000, p. 144), dentre todas as transformações já ocorridas no mundo, "a da informação é a que maior impacto causou no século XX", visto que ela "não obedece a fronteiras", ou seja, não tem espaço determinado de origem e seu significado também passou por alterações.

O conceito de informação, segundo Capurro e Hjorland (2007), no sentindo de conhecimento comunicado, desempenha um papel central na sociedade contemporânea. É comum considerar a informação condição básica para o desenvolvimento econômico, juntamente com o capital, o trabalho e a matéria-prima, mas o que torna a informação especialmente significativa na atualidade é sua natureza digital.

Essas mutações implicam diretamente no profissional da informação, que, diante dos avanços tecnológicos, em face ao crescimento acelerado da informação, deixou de usar apenas as técnicas e passou a exercer, também, o intelectual. Diante disso, o bibliotecário passou a realizar atividades antes não vistas na sua composição profissional, a exemplo do marketing. Com o avanço econômico, científico e tecnológico, surgiram oportunidades de inserção e expansão no mercado de trabalho de novas profissões na área de Ciência da Informação (CI).

Deve-se reconhecer o valor dos conhecimentos e das habilidades da área, mas o profissional deve estar preparado, também, para adquirir novas habilidades. Com as Tecnologias de Informação e Comunicação (TICs), os bibliotecários tiveram que se atualizar e adquirir competências para se comunicar através do novo meio - o digital, 
seja no setor de referência ou em outro. Entretanto, essas novas competências não anularam as teorias consolidadas e se encaixaram em dois perfis profissionais demandados na atualidade: o bibliotecário facilitador de informação e o bibliotecário criador de conhecimento.

Nossa inquietação recai acerca do mercado de trabalho do bibliotecário, diante das transformações sociais, econômicas, políticas e culturais, e o impacto dessas transformações numa sociedade altamente competitiva e cada vez mais exigindo propostas de gestão aderentes ao momento atual de crises. Neste sentido, o marketing se apresenta como aliado para a gestão em unidades de informação, tendo em vista sua eficácia numa perspectiva de alcance de objetivos organizacionais. Diante do contexto enunciado, indagamos: em que medida o bibliotecário contemporâneo se alia ao marketing na consecução dos objetivos organizacionais e quais competências são necessárias para a adequação do marketing na gestão em unidade de informação?

Nosso objetivo é destacar as competências necessárias ao profissional da informação/bibliotecário, no que diz respeito à gestão e ao marketing como elementos constituintes do seu perfil profissional, e ainda mostrar que a gestão e o marketing em unidades de informação são nichos de mercado altamente promissores e dinâmicos.

Assim, este artigo se apresenta em três perspectivas: a informação como elemento transformador na sociedade da informação; o profissional bibliotecário contemporâneo; e a gestão e o marketing em unidade de informação.

\section{A INFORMAÇÃO E SUA FORÇA DE TRANSFORMAÇÃO NA SOCIEDADE DA INFORMAÇÃOO}

A informação é, hoje, a peça fundamental para entendermos as transformações ocorridas no mundo, pois essa informacionalização afeta tanto as sociedades, a economia, as relações de trabalho e o próprio indivíduo em suas relações.

Capurro e Hjorland (2007) enfatizam que o termo informação dentro da CI é o que é informativo para uma determinada pessoa, ou seja, o informativo depende das necessidades do indivíduo. Em consonância, Machlup (1983 apud CAPURRO; HJORLAND, 2007) diz que a informação é um fenômeno humano, pois envolve indivíduos, transmitindo e recebendo mensagens no contexto de suas ações possíveis. 
84 | Ferreira; Guerra | Gestão e marketing em unidade de informação

Para Capurro e Hjorland (2007, p. 164), “informação não é um elemento observável puro, mas construto teórico", ou seja, é um dado interpretado.

Portanto, a informação deve ser estudada como fator essencial que permite o salto para a verdadeira transformação da sociedade. Esse conceito de informação evoluirá à medida que evoluir o conceito de consciência coletiva da sociedade, isto porque, quando uma sociedade evolui, ocorre a transformação advinda da mudança de foco em relação aos fatores de produção e desenvolvimento econômico. A base dessa transformação é que o setor de informação, no qual se inserem as unidades de informação, é intensivo em conhecimento, e não em trabalho manual. 0 valor agregado do conhecimento ou do segmento tecnológico é progressivamente mais importante e incorporado ao bem, provocando a transformação industrial da matéria-prima pelo valor agregado.

A informação é algo muito valioso, e não apenas na sociedade atual, mas em toda a história das sociedades, em virtude de impactar na economia, política, educação e cultura. É importante entender a relevância da informação e do conhecimento para o desenvolvimento da sociedade, porém, a prática profissional da prestação de serviços da rotina cotidiana nem sempre deixa explícito tal importância. Segundo Le Coadic (2004), duas características marcam o futuro da informação: a explosão da informação e a implosão do tempo.

Com o pós II Guerra e o advento das tecnologias, é sabido que houve uma crescente produção de informação, o que conhecemos por "boom informacional”, e este teve impacto no desenvolvimento da $\mathrm{CI}$ e, conseguintemente, no profissional da informação/bibliotecário, e não tão somente neste, mas na sociedade, que passou a ser conhecida por Sociedade da Informação.

Essa Sociedade da Informação exige maiores habilidades do profissional bibliotecário, pois entende que este deva acompanhar o desenvolvimento do seu objeto de trabalho: a informação, pois ela [informação] passa a ser um pressuposto de benefícios, mas também de exclusão, para uma parte da sociedade. Benefícios, pois permite que se tenha acesso a praticamente todo acervo informacional mundial, através da dita internet; exclusão, pois esse acesso é limitado a uma parcela da sociedade, àqueles que têm melhores condições socioeconômicas para se conectar ao mundo.

Conforme Castells (2008), o termo sociedade da informação enfatiza o papel da informação na sociedade. Em concordância, Mattelart (2002, p. 137) exalta que "não 
faltam exortações que insistem na urgência de se estimular ativamente a aquisição de conhecimentos e de competências com o fim de transformar a sociedade da informação emergente em uma sociedade do saber".

Assim, não restam dúvidas de que, na sociedade da informação, todos os ambientes que lidam com a informação precisam ser analisados, a fim de que acompanhem toda essa explosão informacional e contribuam para a melhoria da qualidade de vida das pessoas.

É notório que os últimos anos têm sido caracterizados por transformações econômicas, políticas e sociais, apoiadas nos avanços tecnológicos e numa nova cultura informacional, cuja riqueza encontra-se, cada vez mais, no acesso e uso da informação de forma inteligente para a construção do conhecimento e da sociedade.

Desse modo, e nesse contexto em que a informação tem papel decisivo, abremse inúmeras oportunidades para o profissional da informação/bibliotecário. Em todos os âmbitos profissionais estão aflorando novas necessidades, e o que mais se busca são atitudes como: receptividade perante as mudanças, saber atuar como aliado junto à consecução da missão, objetivos e valores da organização, ser capaz de enfrentar desafios e os compromissos assumidos de maneira inovadora. Assim, o bibliotecário deve ser capaz de situar-se no centro da organização, sendo elemento fundamental para a transformação e adequação desses ambientes às novas tendências e expectativas da sociedade.

\section{O BIBLIOTECÁRIO CONTEMPORÂNEO}

$\mathrm{Na}$ contemporaneidade, a biblioteca adquiriu outro sentido que não apenas depósito de livros, mas sim um lugar onde se formam cidadãos críticos, ou seja, dimensionou suas funções educativas e produtora do conhecimento agregando também sua função social. Esse redimensionamento implicou num redirecionamento das atividades do bibliotecário, onde o mesmo terá que desenvolver competências capazes de honrar as emergentes funções da biblioteca.

A capacidade de colocar em prática as nossas habilidades e conhecimentos seria, então, considerada competência. Para Dutra (2012), a competência tem a ver com diferentes fatores: de um lado, temos a organização que possui um conjunto de competências que lhe são próprias advindas de sua gênese e formação ao longo do Inf. Pauta, Fortaleza, CE, v. 3, n. 1, jan./jun. 2018 
tempo. [...] de outro lado temos as competências que podem ou não estar sendo aproveitadas pela organização. (DUTRA, 2012, p. 23).

No nosso dia a dia, é possível perceber que a influência de nossas habilidades em detrimento da realização com sucesso das nossas atividades nos auxilia no nosso crescimento pessoal, sendo, portanto, mais utilizada a noção de competência como a capacidade de utilizar as nossas habilidades e ser capaz de incorporar valor ao meio em que se insere.

É notório que as competências e habilidades humanas, inseridas no mercado de trabalho por uma profissão, seja bibliotecário ou outra, muitas vezes, sofrem alterações com o decorrer do tempo, o que corrobora as experiências vivenciadas ao longo de sua trajetória - sua inserção geográfica, as demandas sociais. Essas alterações são concebidas por novas funções adicionadas às que já são rotineiras.

Essas mudanças refletem-se, inclusive, nos codinomes utilizados em alusão ao bibliotecário, exemplificados na fala de Carvalho (2002) por profissional da informação, agente de informação, organizadores de informação, profissional do conhecimento, trabalhador do conhecimento, gestor do conhecimento; mas o que todas têm em comum é o papel multifacetado que o bibliotecário assume em suas funções, junção do humanismo à técnica.

Para Fleury, M. e Fleury, A. (2001), da área de Administração, o conceito de competência está associado a verbos como: saber agir, mobilizar recursos, integrar saberes, saber aprender, saber engajar-se, assumir responsabilidade e ter visão estratégica, ou seja, está alinhado à percepção do mercado atual.

O conhecimento gerado resultante das inovações científicas exige um perfil cada vez mais especializado do bibliotecário em virtude dessas mudanças. Esse perfil especializado vai ao encontro do que Castro (2002) chamou de moderno profissional da informação.

O ambiente organizacional faz parte de um universo que abrange a organização, sendo formado por agentes que influenciam interna ou externamente, e ainda direta ou indiretamente a empresa. $\mathrm{O}$ ambiente organizacional é formado por vários integrantes, que, por vezes, podem não ser controláveis. Oliveira (2008) afirma que o ambiente é formado pela reunião de fatores que podem influenciar a operação do sistema.

A administração é um processo contínuo. Sabendo disso, torna-se fácil compreender que uma unidade de informação não é uma organização isolada. Como 
afirma Vergueiro (2007, p. 83), [...] "as unidades de informação são afetadas pelo meio ambiente em que atuam, recebendo influência direta de seu contexto econômico-social". E o ambiente organizacional faz valer a necessidade de um ciclo constante de gestão em qualquer tipo de organização.

0 atual perfil do bibliotecário exige que o profissional seja capaz de lidar com várias responsabilidades, realizando atividades para além das técnicas (catalogar, indexar, classificar). A gestão de unidades de informação se mostra um tema com bastante relevância, diante da crescente importância dada às unidades de informações, portanto, um profissional que tenha a competência e gosto de gerir/administrar estes espaços encontra-se em vantagem no mercado de trabalho.

\section{GESTÃO E MARKETING EM UNIDADE DE INFORMAÇÃO}

As organizações estão modificando as suas condutas de gestão e marketing. No século XX, o movimento já mencionado [boom informacional] foi relacionado com a gestão do acúmulo de informações produzidas e registradas, que, para a Biblioteconomia, impactou no tratamento, organização e disseminação de todas essas novas informações.

As grandes transformações ocorridas ao longo do tempo culminaram na forma como a informação era vista, sendo agora de forma rápida e globalizada. A gestão tornase, então, um ponto de grande preocupação do bibliotecário, uma vez que, na sociedade da informação, os usuários/clientes estão cada vez mais exigentes e desejam conteúdos selecionados e prontos num curto espaço de tempo. Cabe ao bibliotecário desenvolver estratégias para poupar o tempo do usuário, fazendo luz a uma das Leis de Ranganathan.

Valls e Vergueiro (2006, p. 121) destacam a importância de analisar as tendências sobre a aplicação da qualidade em serviços de informação:

Se evidencia uma certa predisposição por parte dos dirigentes destes serviços em modernizar as práticas gerenciais utilizadas, buscando inclusive novas formas de organização do trabalho, muito mais focado no atendimento das necessidades dos usuários, em contraposição à disponibilização de documentos e informações de forma passiva.

Levando em consideração a gestão de serviços, o profissional deve se preocupar com o desempenho do que está sendo oferecido, pois a qualidade é o que trará ao cliente 
a satisfação sobre o serviço informacional prestado e ao gestor a certeza de que está administrando corretamente, ou mesmo a análise sobre o que se pode melhorar.

As organizações em geral necessitam de um marketing forte - entendendo que este é a alma do negócio -, e no caso das bibliotecas não seria diferente, visto que o sucesso de qualquer empresa advém de satisfazer os desejos dos clientes/usuários, que representam a base social e econômica de qualquer organização. Apesar de o marketing em unidades de informação ser ainda pouco utilizado, não se deve menosprezar a sua existência.

0 marketing, atualmente, é dito como um processo gerencial que engloba várias atividades, como a análise, desenvolvimento e avaliação. Entretanto, historicamente, de acordo com So (2007, p. 37), a designação da palavra marketing surgiu pela primeira vez na década de 1950. Embora o processo já existisse, foi somente naquele período que surgiu a definição de seu conceito. A atividade de marketing já era realizada, porém, sob diferentes enfoques, cada um deles relacionado a um determinado cenário econômico.

A partir dos anos 60, iniciou-se uma expansão da aplicação das ferramentas do marketing para os mais diversos setores. Por muitas vezes, o marketing foi relacionado apenas às atividades com fins lucrativos; entretanto, a partir da década de 70, ocorreu uma ampliação desta área de competência do marketing. A sua apropriação pela área cultural se concretizou pela introdução de estratégias nos setores filantrópico e social, com a denominação de marketing social.

Segundo Kotler (1978, p. 20), o marketing

Exige a oferta de valor a alguém, em troca de valor. Através das trocas, várias unidades sociais - indivíduos, pequenos grupos, organizações, nações inteiras obtêm os insumos de que precisam. Pela desistência de alguma coisa, elas adquirem alguma outra coisa em seu lugar. Essa alguma outra coisa é normalmente mais valiosa do que aquilo de que se desistiu, o que explica a motivação da troca.

Compreende-se, então, que o marketing é uma moeda de troca, onde ambos instituição/biblioteca e cliente/usuário - ganham valor informacional. Ainda segundo Kotler (2000, p. 25), o marketing "é visto como a tarefa de criar, promover e fornecer bens e serviços a clientes”, papel este também das bibliotecas.

Desse modo, podemos dizer que o marketing tem uma orientação voltada para o usuário, especificamente para a satisfação dele, trazendo esta satisfação aos propósitos da organização/biblioteca, visto que a função da biblioteca é atender as demandas do 
seu público. Sendo assim, o marketing pode ser utilizado como uma forma de captar a atenção dos usuários, ao passo que ele surge como um instrumento auxiliar planejado e que visa à criação de estratégias para se atentar às mudanças que, de alguma forma, possam se voltar como ameaças aos serviços promovidos pela instituição, ou, como já mencionado anteriormente, aliado à satisfação dos usuários, ou seja, ao modo como eles - usuários - veem a qualidade dos serviços, alertando aos bibliotecários melhorias e sugestões.

Assim como empresas privadas, as organizações culturais também estão sujeitas a ameaças, e por isso Wood (1987, p. 173-174) diz que:

\begin{abstract}
O marketing ajuda os bibliotecários e o pessoal da informação a melhorar sua reputação, tanto dentro das instituições quanto como profissão dentro da sociedade [...] os bibliotecários são frequentemente ingênuos quando se trata de política interna das organizações onde trabalham [...] eles têm de promover um bom trabalho de relações públicas para estarem seguros de que sejam ouvidos e que estejam bem representados.
\end{abstract}

Pode-se dizer, então, que o papel do marketing em unidades de informação é a promoção das atividades, de modo que satisfaça às necessidades dos usuários e, assim, justifique a existência da biblioteca, ao passo que o retorno dessa satisfação seja visto como lucro para a instituição. 0 marketing é mais que venda, é, portanto, visto como uma relação de troca usada pelos bibliotecários com o propósito de expandir seu mercado, ao mesmo tempo em que introduz inovações na biblioteca. E isso chama a atenção dos usuários, despertando seu interesse de participar efetivamente dessas atividades.

O marketing sempre foi encarado como uma técnica de vender produtos, entretanto, hoje, ele é a arte de construir relacionamentos. Assim, nasce o marketing de relacionamento. 0 marketing de relacionamento, de acordo com McKenna (1992), tratase de um novo marketing, sendo que a solução real obviamente não é mais o marketing, e sim o melhor marketing. E isso significa um marketing que encontra um modo de integrar o cliente à empresa, como forma de criar e manter relação entre a empresa e o cliente. É importante salientar que o marketing de relacionamento está sempre voltado para o usuário. 
90 | Ferreira; Guerra | Gestão e marketing em unidade de informação

\section{O PROFISSIONAL BIBLIOTECÁRIO: nuances na gestão e marketing em unidades de informação}

As TICs impulsionaram mudanças em diferentes cenários, desde as áreas de Ciência \& Tecnologia (C\&T), bem como nas de Administração e Informação. Milanesi (2002) discorre sobre a complexidade do reconhecimento social do profissional bibliotecário, visto que o autor percebe que nem sempre é o bibliotecário quem ocupa os cargos de liderança. Entretanto, essa visão vem mudando, pois é possível enxergar o bibliotecário atuando enquanto líder/gestor cada vez mais presente nas organizações.

Segundo Ferreira (2016), o marco inicial dos estudos sobre o mercado de trabalho e as competências dos profissionais da informação da área da CI data de 1969, com um estudo dirigido por Wasserman e Bundy, nos Estados Unidos. Esses autores iniciaram a discussão acerca da mudança do mercado de trabalho versus a atuação do profissional da informação.

Um estudo importante sobre a descrição de perfis de atuação do profissional, e que se destaca por ser referência para a profissionalização do bibliotecário, para os gestores de biblioteca e para as escolas de Biblioteconomia, é o documento Consejo de Cooperacion Bibliotecaria - Grupo de Trabajo sobre perfiles profesionales, de 2013. Nessa mesma linha de raciocínio, Moreiro e Tejada Artigas (2004) trazem uma reflexão a respeito das competências definidas pelo MERCOSUL e pela União Europeia e onde estas se relacionam, por exemplo: conhecimento técnico; gestão e direção; habilidades de comunicação e expressão linguística; habilidades informáticas; atitudes pessoais e habilidades criativas.

Diante de um mundo consumista, competitivo e cheio de incertezas, devemos transformar ameaças em oportunidades inovadoras. A gestão é o processo que visa atingir os objetivos e metas de uma organização, de forma eficiente e eficaz. De acordo com Alves e Oliveira (2016, p. 83),

O bibliotecário com a visão de gestor de pessoas, comprometido com a motivação e com a gerência de recursos e serviços informacionais são essenciais para que os objetivos da biblioteca sejam almejados. Nesse aspecto, a necessidade de capacitação contribuirá com sua formação enquanto responsável pelo setor, pois junto com os seus colaboradores poderão ofertar para a comunidade uma disseminação de informação com mais credibilidade. 
Ou seja, o bibliotecário enquanto gestor é uma função que vem ganhando espaço e importância, diante das mudanças do ambiente, além de contribuir, de forma mais eficaz e eficiente, com a disseminação da informação.

Amaral (1993, p. 130), por sua vez, "sugere que as bibliotecas adotem a administração orientada para o marketing como forma inovadora e capaz de melhorar o desempenho dessas organizações conduzindo-as a uma atuação efetiva junto aos seus públicos". A autora conclama seus pares a estarem atentos aos avanços tecnológicos, assim como sugere aos bibliotecários brasileiros que procurem "se antecipar às necessidades de informação de seus usuários". Revela preocupação com as bibliotecas que ficarão obsoletas se não compreenderem e não comunicarem a importância dos seus serviços automatizados. Diante disso tudo, a autora ressalta o papel dos gerentes das unidades de informação, responsáveis pela motivação de sua equipe; de manter a biblioteca em reconhecida atividade; e garantir o enfoque mercadológico da gerência de bibliotecas.

Segundo Ottoni (1996, p. 171),

0 marketing em unidades de informação pode ser entendido como uma filosofia de gestão administrativa na qual todos os esforços convergem em promover, com a máxima eficiência possível, a satisfação de quem precisa e de quem utiliza produtos e serviços de informação.

O marketing direto, para Silveira (1992, p. 22-23),

[...] é um processo de gestão que utiliza a comunicação interativa em forma de diálogo permanente entre a organização e o cliente, mantendo uma base de dados para registrar e medir a demanda dos produtos e adequação do preço, a eficiência dos diferentes meios de comunicação utilizados, a eficácia da própria comunicação com o cliente e a efetividade das transações na totalidade do Sistema de Informações de Marketing (SIM). 0 marketing direto é também uma alternativa para manter uma relação pessoal e personalizada com os consumidores, posto que (sic) permite sua localização, identificação e uma comunicação interativa com eles.

No marketing de relacionamento, o cliente ajuda a empresa a fornecer o pacote de benefícios que ele valoriza, sendo um esforço contínuo e colaborativo entre empresa e cliente, funcionando em tempo real. E as empresas estão pretendendo desenvolver confiança e lealdade junto a seus consumidores finais.

Figueiredo (1991, p. 124) conclui que: 
O conceito de marketing inverte a ordem das prioridades em um sistema de informação, no sentido de que, em vez de fazer com que os usuários/consumidores façam uso dos produtos que têm a oferecer, o sistema cria produtos específicos que vão ao encontro das necessidades e interesses dos usuários. Coloca, assim, a eficácia em plano superior ao da eficiência, sem abandonar, contudo, a meta da eficiência. Esta abordagem pode assegurar a plena utilização dos serviços/produtos do sistema de informação, meta final a ser alcançada por todo administrador.

Targino $(2006,125)$ reafirma que o bibliotecário precisa estar ciente da evolução científica e tecnológica; entretanto, a mesma diz que essa evolução deve ser acompanhada também pelos usuários, dando uma nova função ao bibliotecário, que é o "papel de partícipe da educação digital em prol da coletividade onde atua".

É visível que o objeto de trabalho do profissional de informação é a informação, e que esta vem sofrendo alterações além das paradigmáticas e da evolução das TICs, que, para Valentim (2000), é a questão da importância que a sociedade atribui à informação, ou seja, isso mostra que o bibliotecário deve, sempre, antecipar-se às necessidades da sociedade. Devemos ser o que Mueller (1996, p. 271) propõe: um profissional "vivo e atuante".

Conforme Valentim (2000), a formação do bibliotecário supõe o desenvolvimento de determinadas competências e habilidades e o domínio dos conteúdos da Biblioteconomia, além de entender que os bibliotecários devem estar preparados para enfrentar, com proficiência e criatividade, os problemas de sua prática profissional, produzir e difundir conhecimentos, refletir criticamente a realidade que os envolve e buscar aprimoramento contínuo.

0 profissional que atua em unidades de informação precisa estar preparado para enfrentar essa realidade, percebendo que a disseminação das técnicas mercadológicas poderá contribuir para a efetiva mudança de atitude profissional, pois representa uma oportunidade de inovação. A opção pela orientação de marketing na administração das unidades de informação propiciará que os recursos sejam melhor aproveitados, incluindo-se, nesse contexto, o aproveitamento máximo da potencialidade das novas tecnologias disponíveis para a captação e recuperação da informação.

Portanto, é interessante refletir sobre as vantagens do marketing como ferramenta gerencial para melhorar o desempenho das unidades de informação. Essa reflexão poderá contribuir no sentido de que as unidades de informação cumpram satisfatoriamente o seu papel como organizações essenciais para o desenvolvimento social, econômico, político e cultural da sociedade. 


\section{CONCLUSÃo}

Indubitavelmente, as mudanças no mundo estão afetando os modelos tradicionais do fazer do profissional da informação, devido ao seu objeto de trabalho ser a informação. Esse objeto, portanto, tem sido afetado sistematicamente pelas tecnologias de informação, modificando seu formato, suporte, tratamento e disseminação, e influindo no ser bibliotecário. Outro fator que interfere na informação é a sociedade, mais precisamente o valor que a mesma dá à informação, e isso está diretamente ligado ao seu desenvolvimento, ou seja, quanto mais desenvolvido é um país, maior é o nível de produção informacional.

O profissional da informação deve perceber seu papel de processador e filtrador de informação e usá-lo de forma coerente e eficiente, voltado para o usuário. Novas mediações da informação, envolvendo profissional e usuário, devem ser sempre estudadas e implementadas, estruturando a disseminação e distribuição da informação. A atualização contínua do profissional é fundamental. Essa capacidade de renovação influencia diretamente a capacidade de trabalho e produtividade de um profissional e, conseguintemente, da sociedade.

Devemos reconhecer o valor dos conhecimentos e das habilidades básicas do profissional bibliotecário, mas o mesmo deve estar preparado para adquirir novos conhecimentos também, pois a diversidade das funções do profissional da informação constitui um leque de novas competências que podem ser aplicadas em diversos contextos e ambientes, mas, antes de tudo, são necessárias novas atitudes e a transformação de entendimento do profissional.

O profissional da informação pode e deve usar a informação como fator de competitividade, trazendo-a como contribuinte na tomada de decisão, insumo na inovação, fator de produção e gestão, saindo da zona de conforto do indexar/catalogar/classificar. Dessa forma, acreditamos que o profissional da informação/bibliotecário em formação deve ter uma consciência em torno de sua prática futura, nas articulações do saber e do saber fazer, de modo a (re)significar os paradigmas e conceitos inerentes à Biblioteconomia. E, para isto, os cursos formadores devem acompanhar as mudanças e as novas exigências sociais e se preocupar em modificar seus currículos em função de inserir no mercado de trabalho profissionais adequados com as aptidões e competências da atualidade. 
94 | Ferreira; Guerra | Gestão e marketing em unidade de informação

\section{REFERÊNCIAS}

ALVES, Márcia Valéria; OLIVEIRA, Magali Araújo Damasceno de. Gestão de unidades de informação: bibliotecário como gestor e líder. Bibliocanto, Natal, v. 2, n. 1, p. 70-82, 2016.

AMARAL, S. A. do. Abordagem mercadológica em bibliotecas e serviços de informação. In: SILVEIRA, A.; AMARAL, S. A. do. Marketing em unidades de informação: estudos brasileiros. Brasília, DF: IBICT: SENAI, 1993.

CAPURRO, Rafael; HJORLAND, Birger. 0 conceito de informação. Perspectivas em Ciência da Informação, Belo Horizonte, v. 12, n. 1, p. 148-207, jan./abr. 2007.

CARVALHO, Kátia de. 0 profissional da informação: o humano multifacetado. DataGramaZero: Revista de Ciência da Informação, Rio de Janeiro, v. 3, n. 5, out. 2002.

CASTELLS, Manuel. A sociedade em rede. 11. ed. São Paulo: Paz e Terra, 2008. v. 1.

CASTRO, César Augusto de. Formação do profissional da informação: abordagem críticoreflexiva. $I n$ : . (Org.). Ciência da Informação e Biblioteconomia: múltiplos discursos. São Luiz: EDFAMA: EDUFMA, 2002. p. 185-199.

CASTRO, César Augusto de. Profissional da informação: perfis e atitudes desejadas. Informação \& Sociedade: Estudos, João Pessoa, v. 10, n. 1, p. 142-156, 2000.

CUNHA, A. G. da. Dicionário etimológico da língua portuguesa. 2. ed. Rio de Janeiro: Nova Fronteira, 1997.

DUTRA, Joel Souza. Competências: conceitos e instrumentos para a gestão de pessoas na empresa moderna. São Paulo: Atlas, 2002.

FERREIRA, Danielle Thiago. As novas competências do profissional da informação bibliotecário: reflexões e práticas. In: RIBEIRO, A. C. M. L.; Ferreira, P. C. G. (Org.). Biblioteca do século XXI: desafios e perspectivas. Brasília, DF: Ipea, 2016. p. 79-90.

FIGUEIREDO, N. M. de. Marketing em sistema de informação. In: (Org.).

Metodologias para promoção do uso da informação: técnicas aplicadas particularmente em bibliotecas universitárias e especializadas. São Paulo: Nobel: APB, 1991.

FLEURY, M. T.; FLEURY, A. Construindo o conceito de competência. Revista de Administração Contemporânea, v. 5, n. especial, 2001.

KOTLER, Philip. Marketing para organizações que não visam o lucro. São Paulo: Atlas, 1978.

LE COADIC, Yves-François. A ciência da informação. Brasília, DF: Briquet de Lemos/Livros, 2004. 
MATTELART, Armand. História da sociedade da informação. São Paulo: Edições Loyola, 2002.

MCKENNA, Regis. Marketing de relacionamento: estratégias bem-sucedidas para a era do cliente. 10. ed. Rio de Janeiro: Campus, 1992.

MILANESI, Luis. A informação do informador. Informação \& Informação, Londrina, v. 7, n. 1, p. 07-40, jan./jun. 2002.

MOREIRO, J. A.; TEJADA ARTIGAS, C. M. Competencias requeridas para el ejercicio de las profesiones de la informacion: valoracion de las listas relacionales de mercosus y de la union europea. Informação \& Informação, Londrina, v. 9, n. 1, jan./dez. 2004.

MUELLER, Suzana Pinheiro Machado. Formação profissional e educacional continuada que profissional devemos ser? In: SIMPÓSIO BRASIL-SUL DE INFORMAÇÃO, 1996, Londrina. Anais... Londrina: Editora UEL, 1996. p. 253-272.

OLIVEIRA, Djalma Pinho Rebouças de. Planejamento Estratégico: conceitos, metodologias e práticas. 25. ed. São Paulo: Atlas, 2008.

OTTONI, H. M. Bases de marketing para unidades de informação. Ciência da Informação, Brasília, v. 25, n. 2, p. 171-176, 1996.

SILVEIRA, A. A literatura brasileira de marketing em bibliotecas e serviços de informação: de julho de 1977 a julho de 1992. In: SILVEIRA, A.; AMARAL, S. A. do. (Org.). Marketing em unidades de informação: estudos brasileiros. Brasília: IBICT: SENAI, 1993.

SO, Denise Rodrigues. A segmentação de clientes em bibliotecas. 2007. 189 f. Dissertação (Mestrado) - Universidade de São Paulo, São Paulo, 2007.

TARGINO, Maria das Graças. A profissão do bibliotecário no Brasil. In: Olhares e fragmentos: cotidiano da Biblioteconomia e ciência da informação. Teresina: EDUFPI, 2006. p. 119-127.

VALLS, V. M.; VERGUEIRO, W. A gestão da qualidade em serviços de informação no Brasil: uma nova revisão de literatura, de 1997 a 2006. Perspectivas em Ciência da Informação, Belo Horizonte, v. 11 n. 1, p. 118-137, jan./abr. 2006.

VALENTIM, Marta Lígia Pomim. Atuação e perspectivas profissionais para o profissional da informação. In: . Profissionais da informação: formação, perfil e atuação profissional. São Paulo: Polis, 2000. p. 135- 152.

VALENTIM, Marta Lígia Pomim. Profissional da informação: formação, perfil e atuação profissional. In: Profissionais da informação: formação, perfil e atuação profissional. São Paulo: Polis, 2000. p. 7-29. 
96 | Ferreira; Guerra | Gestão e marketing em unidade de informação

VERGUEIRO, W. Gestão de pessoas em unidades de informação. In: VERGUEIRO, W.; Angélica C. S. D. (Org.). Administração de unidades de informação. Rio Grande: Ed. da FURG, 2007. p. 81-92.

WO0D, Douglas. Melhorado sua imagem: como promover a biblioteca ou serviço de informação. In: SILVEIRA, Amélia (Org.). Marketing em bibliotecas e serviços de informação: textos selecionados. Tradução: Amélia Silveira e Marília Salgado Gontijo. Brasília, DF: IBICT, 1987. p. 173-185.

\section{SOBRE AS AUTORAS}

\section{Jade Gomes de Sousa Ferreira}

Graduanda em Biblioteconomia pela Universidade Federal do Ceará (UFC).

E-mail: jadegomesdesousa@hotmail.com

\section{Maria Aurea Montenegro Albuquerque Guerra}

Doutoranda em Educação Brasileira pela Universidade Federal do Ceará (UFC). Professora do Departamento de Ciências da Informação da Universidade Federal do Ceará (UFC).

E-mail: aureamag@yahoo.com.br

Recebido em: 13/05/2018; Aceito em: 26/05/2018; Revisado em: 03/06/2018.

\section{Como citar este artigo}

FERREIRA, Jade Gomes de Sousa; GUERRA, Maria Aurea Montenegro Albuquerque. Gestão e marketing em unidade de informação: competências do profissional da informação. Informação em Pauta, Fortaleza, v. 3, n. 1, p. 81-96, jan./jun. 2018. 